\title{
Impacts of hospital waste management on the health and environment of Ogbomoso area, Oyo state
}

\begin{abstract}
Wastes, especially, hospital wastes have been known to have serious implication on the health and environment where they are not properly managed. Hence, this study assessed waste management practices in different hospitals (Public Primary Health Centre, Private and Referral Hospitals) as they affects health and environment.

Secondary statistical data were obtained from different hospital waste disposal locations. Waste generation, segregation, storage, collection, transportation and disposal level were investigated. Questionnaires were used as research tools. The questionnaire was designed to inquire of hospital information like year of establishment, area of specialization; personnel information like personnel characteristics; age, educational qualification; working experience; type of waste available in the hospital; waste management strategy/handling methods; record of waste generation and methods of disposal.

Waste handling method and treatment before disposal recorded low value of $11 \%, 0 \%$ and $11 \%$ colour coding in referral hospital, private and public primary health centre respectively. Very little record of waste in most of the hospital investigated. Training of staff on waste handling and disposal were valued at $12 \%, 33 \%$ and $13 \%$ in Referral, Private and Public health centre respectively. Almost all the hospital investigated employed self disposal with no reliance on government. No appreciable recycling; Referral (2\%), Private (11\%), and public primary health centre (7\%).

The results from this research indicated that there is need for strict compliance to clearly stipulated rules that apply to generation, collection, receive, storage, transport, treatment, disposal, and handling of medical waste. There is observed lapses in

medical waste disposal management which call for urgent attention.
\end{abstract}

Keywords: waste, disposal, handling, segregation and autoclaving
Volume 2 Issue $6-2018$

\author{
Adeoye AO,' Akande EA,' Lateef $\mathrm{A}^{2}$ \\ 'Department of Food Science and Engineering, Ladoke Akintola \\ University of Technology, Nigeria \\ ${ }^{2}$ Department of Pure and Applied Biology, Ladoke Akintola \\ University of Technology, Nigeria
}

\begin{abstract}
Correspondence: Adeoye AO, Department of Food Science and Engineering, Ladoke Akintola University of Technology, Ogbomoso, Oyo state, Nigeria,
\end{abstract}

Email eaakende@lautech.edu.ng, aodaoye@lautech.edu.ng

Received: April 20, 2018 | Published: December 13, 2018

\section{Introduction}

Wastes are materials generated from human and animal activities and are discarded as useless or unwanted. ${ }^{1}$ Waste includes all items that people no longer use, which they either intend to get rid of or have already discarded, they are also referred to as rubbish or garbage. Items considered as waste may include household wastes, garden wastes, hospital wastes, old paint containers, etc. Thus men's daily activities can give rise to a large variety of different wastes arising from different sources. ${ }^{2}$ The rapid rate of urbanization, lack of effective land use and effective maintenance system of essential services have led to grave environmental problem, The magnitude of the solid waste problem worldwide is often reflected in the print media. ${ }^{3}$ In a study conducted by UNIDO, apart from industrial waste, another major, most dangerous source of waste generation is hospital, clinics and pathological laboratories. ${ }^{4}$ Although, hospital waste may tend to constitute a small fraction of the Municipal Solid Waste (MSW), the potential environmental and health hazard could be deleterious if not properly handled.

Medical wastes are wastes generated by hospital or clinic laboratories as the result of surgeries, autopsies, or other medical procedures. It can also be generated at home. However, wherever it is generated, medical waste have potential to transmit disease to other people. ${ }^{5,6}$ As a result, medical waste has become a public health issue that attract attention in both industrialized and developing countries. $^{7}$ Hospital is one of the complex institutions which are frequented by people from every walks of life in the society, without distinction between age, sex, race and religion. This is different from normal inhabitant of hospital (the patient and staff), however, all these people produce waste which is increasing in amount and type due to advances in scientific knowledge. ${ }^{8}$ Hospital waste may be infectious or non-infectious. The non-infectious wastes come from the hospitals environments like the grasses and flowers and are of less heath risk. The infectious hospital waste, in addition to the risk for patients and personnel who handles it, poses threats to public health and environment. ${ }^{9}$ Due to enormous health and aesthetic effect on our cities and town, so many government agencies are set up to regulate and manage waste that are generated from different sources in our society including those from hospital wastes. Few of these agencies include: Federal Environmental Protection Agency (FEPA), National Environmental Standard and Regulation Enforcement (NESRE), Municipal Solid Waste Management (MSWM), etc. These agencies and ministries made regulations and guidelines to safe guide and protect our environment and health of the people.

According to United State ministry of environment and forestry notification on waste management, every hospital generating biomedical waste need to, (i) set up requisite treatment facilities on site or ensure requisite treatment of waste at common treatment facilities, (ii) No untreated bio-medical waste shall be kept or store beyond a 
period of $48 \mathrm{~h}$, (iii) It is the duty of every occupier i.e. the owner of institution were medical waste are generated to take all steps to ensure that waste generated is handle without any adverse effect to human health and environment, (iv) Bio-medical waste should be transported within the hospital by means of wheeled trolleys, container or carts that are not used for any other purposes, (v) generally waste like garbage, garden refuse, waste paper, waste plastic container should join the stream of domestic refuse, (vi) sharps should be collected in punctured proof containers, (vii) bags and container for infectious waste should be marked with biohazards symbol and (viii) highly infectious waste should be sterilized by autoclaving. ${ }^{10}$

Hospital wastes are categorized and each category can be generated in the hospital depending on the capacity and type of the hospital. Such as maternity, general word, clinic laboratory and specialist hospital. In each of these units, the level of waste generated varies relatively. But the waste are better grouped into the following: (i) Human blood and blood products, (ii) cultures and stocks of infectious agents, (iii) pathological waste, (iv) sharps, (v) glassware/ broken glassware, (vi) contaminated equipment/junk equipment, (vii) chemical/radioactive. ${ }^{11}$ Some categories of hospital waste are regarded as biological waste. This group of waste disposal which include non-human disease agent/ equipment that has come in contact with the non-disease example general zoonotic vectors used in research and culture used in plant pathology research, the equipment such as petri-dishes and pipette as long as they do not contain human disease agent, are not regulated. However, good laboratory practices would include autoclaving of all biological waste prior to disposal. All biological waste can be disposed with normal trash in as much as it does not contain infectious material. ${ }^{11-13}$

Solid waste includes all other waste and materials which have not been exposed to human infections agent are items that may be recycled or dispose in the trash. Chemical or Radioactive waste must not be disposed of as solid waste or Medical waste. Human blood and blood products are classified and managed as medical waste because of the possible presence of infectious agent that can cause blood borne disease. Waste in this category includes bulk blood and blood products as well as smaller quantities of blood samples drawn for testing or research. Waste of human blood must be treated by steam sterilization. After sterilization, the liquid portion may be safely poured off into a sanitary sewer drain. Animal blood is not regulated as medical waste unless it has been intentionally exposed to a human infections agent and is capable of transmitting the disease back to humans. Cultures and stock of infections agents, regardless of storage methods must be managed as medical waste. Pathological waste must be regulated and treated as medical waste. Sharps, needle and syringes, intravenous needle and tubing, scalped blades lances and other such devices are regulated as medical waste. All sharps must be placed in an approved sharps container; sharps that have been exposed to human disease agent must be autoclaved prior to pickup. ${ }^{11,14}$ Glassware exposed to human infectious must be managed as sharp until it has been autoclaved. These include pipettes, capillary tubes, test tubes, stir rods and other laboratory equipment. All glassware that has been exposed to human infectious agent must be autoclaved prior to disposal. Glassware that has not been exposed to human disease agent is not regulated as sharp, broken glassware should be placed into a container designed for such materials and either recycled or disposed. ${ }^{11}$

The occupational health effect of medical and other hazardous waste depend on the duration of exposure of the hazardous waste on the body of the victim. It also depends on the dose of toxic compounds that enter the body from the waste. ${ }^{15}$ Unmanaged hospital waste constitutes hazards to human body through different routes of exposure thus cause ill health and economic loss. Injuries and accidental cuts due to handling of medical waste that contained sharps and needles are common with municipal waste workers that handle hospital waste. Contacting diseases due to handling contaminated infectious waste are common too. Infection and disease which may result from waste may be of bacterial origin e.g. tetanus, anthrax, cholera, diarrhoea; fungal infections e.g. candida, cryptococcus; viral infection e.g. hepatitis, poliomyelitis; other hazardous medical waste like benzene, carbon tetrachloride pose risk to workers handling them. The underground drinking water may be contaminated by leakages from landfill to the aquifer and surface drinking water thereby posing health risk to the people. ${ }^{12}$ Hospital wastes have been known to have serious implication on the health and environment where they are not properly managed as a result, the impacts of Hospital Waste Management on the Health and Environment needed to be assessed for proper recommendation. ${ }^{16}$

Hence, this study assessed waste management practices in different hospitals (Public or Primary Health Centre, Private and Referral Hospitals) as they affects health and environment.

\section{Materials and methods}

Data are collected with the use of questionnaire as research tools from the hospital waste management unit. The questionnaires parts: Part A; Hospital information: year of establishment, area of specialization. Part B; personal information which include, age educational qualification, working experience. Part $\mathrm{C}$; type of waste available in the hospital: radioactive waste, chemical waste, biological waste, flammable waste. Part $\mathrm{D}$; waste management strategy/handling methods: separation at source, colour coding, sharps segregation, autoclaving/ incineration, any other methods. Part E; record of waste generation, storage facilities, waste disposal vehicle, waste management team, any regular training, any waste handling material/ equipment. Part F, investigation on disposal/ treatment. The questionnaires were administered using these groupings: (i), Referral hospital, (ii) Primary health, (iii) Private hospital. The ages of establishment of the hospital were presented in range, (56-101) years for referral hospital, (12-28) years for private hospital and (18$31)$ years for primary health centre. The response were collected and recorded into appropriate group and the responses were interpreted according to the coded value.

\section{Results and discussion}

The description of the hospital surveyed was given in Table 1 . Out of questionnaire sixty distributed, 16 copies ware recovered from referral hospital, 9 from private, 15 from primary health centre. The respondents are doctors and nurses, with working experiences ranging from 2 to 42 years; medical waste management consideration is presented in Table 2 showing tracking program; wastes monitoring; wastes treatment facilities and waste management plans were assessed and the level of compliance was as presented in the table. Medical waste composition in percentage was presented in Table 3, with waste composition as radioactive, chemical, biological and flammable waste. Table 4 present waste generations in percentage while waste handling methods was presented in Table 5. Disposal method was presented in Table 6 which shows level of method applied in disposal of waste. 
Table I Descriptive analysis of surveyed hospitals

\begin{tabular}{|c|c|c|c|c|c|}
\hline Hospital grouping & Description & $\begin{array}{l}\text { Work experience } \\
\text { range (year) }\end{array}$ & $\begin{array}{l}\text { Number of } \\
\text { questionnaire }\end{array}$ & Age of estab. & $\begin{array}{l}\text { Respondent } \\
\text { questionnaire }\end{array}$ \\
\hline \multirow[t]{2}{*}{ Referral } & $\begin{array}{l}\text { Handles special and severe } \\
\text { cases. }\end{array}$ & $2-26$ & 16 & $56-|0|$ & 9 Doctors \\
\hline & & & & & 7 Nurses \\
\hline \multirow[t]{2}{*}{ Private } & $\begin{array}{l}\text { Handle general and } \\
\text { specialized cases }\end{array}$ & $2-42$ & 9 & $12-28$ & 6 Doctors \\
\hline & & & & & 3 Nurses \\
\hline \multirow[t]{2}{*}{ Primary health Centre } & $\begin{array}{l}\text { Minor cases or ailments and } \\
\text { delivery. }\end{array}$ & $4-22$ & 15 & $18-37$ & 2 Doctors \\
\hline & & & & & I3Nurses \\
\hline
\end{tabular}

Table 2 Medical waste management consideration

\begin{tabular}{lllll}
\hline Designation & Tracking programme & Monitoring & Treatment facility & Management plan \\
\hline Referral & None & None & Present & Absent \\
Private & None & None & Present & Absent \\
Primary H.C. & None & None & Present & Absent \\
\hline
\end{tabular}

Source: field survey, 2008

Table 3 Medical waste composition in percentage

\begin{tabular}{lll}
\hline Types of waste & Frequency & Percentage \\
\hline Radioactive & II & 27.5 \\
Chemical & 24 & 60.5 \\
Biological & 37 & 93.5 \\
Flammable & 23 & 57.5 \\
Multiple & 95 & 237.5 \\
\hline
\end{tabular}

Source: field survey, 2008

Table 5 Waste handling methods
Table 4 Waste generated in percentage

\begin{tabular}{lcccc}
\hline Hospital & Radioactive & Chemical & Biological & Flammable \\
\hline $\begin{array}{l}\text { Referral } \\
\text { hospital }\end{array}$ & 38.3 & 43.8 & 100 & 27 \\
$\begin{array}{l}\text { Private } \\
\text { hospital }\end{array}$ & II.I & 100 & 100 & 77.8 \\
$\begin{array}{l}\text { Primary H. C. } \\
\text { 2. }\end{array}$ & 53.8 & 78.6 & 78.6 \\
\hline
\end{tabular}

Source: field survey, 2008

\begin{tabular}{llllll}
\hline Hospital & Separation at source & Color coding & Sharp segregation & Auto/Incineration & Others \\
\hline Referral hospital & 60.4 & II.I & 54.8 & 32.6 & 45.2 \\
Private hospital & 44.4 & II.I & 55.6 & 22.2 & 66.7 \\
Primary H. C. & 26.8 & 0 & 6.3 & 0 & 92.8 \\
Total & 138.8 & 22.2 & 116.7 & 54.8 & 204.7 \\
\hline
\end{tabular}

Others: Flushing of sink, antiseptic treatment and open dump.

Source: Field survey, 2008.

Table 6 Disposal methods

\begin{tabular}{lllllll}
\hline Hospital & Incineration & Burning & Composting & Land fill & Drop off centre & Autoclaving \\
\hline Referral hospital & 56.4 & 95 & 43.7 & 32.5 & 31.5 & 18.3 \\
Private hospital & 0 & 77.8 & 22.2 & 33.3 & 55.6 & 11.1 \\
Primary H. C. & 0 & 86.6 & 58 & 43.7 & 38.4 & 7.2 \\
\hline
\end{tabular}

Source: Field survey, 2008.

From Table 2, it can be seen that there is no tracking programme for all the hospital surveyed. There is no monitoring team and management plan for waste disposal. There are treatment facilities but needed improvement. From Table 3, the highest waste across the hospital is the biological waste with $93.5 \%$ while the lowest is the radioactive. Table 4 shows that biological waste is the highest waste generated across the hospital with $100 \%$ while the lowest is the radioactive waste. Table 5 showed that the most practiced method of disposal involved flushing of the sinks, antiseptic treatment and open dump. Table 6 indicate that burning is the highest disposal method used $95 ; 77.8 ; 86.6 \%$ respectively for referral private, and public primary center. While autoclaving is the lowest treatment method used $18.3 ; 11.1 ; 7.2 \%$ respectively referral private and public health center. Relative to the size of the referral hospitals, there are very low levels of waste management strategy, there are inadequate storage facilities for waste $(25 \%)$, waste disposal vehicle $(12.5 \%)$. 
The handling method is very appreciable with $94 \%$. Waste recycling is generally poor $(2 \%)$ in all the referral hospitals.

Biological wastes were found to be the highest waste generated across the hospitals surveyed with $93.5 \%$, while radioactive waste is $27 \%$ Waste handling methods (Table 7) revealed that methods that will make disposal process easier for the final waste disposal were

Table 7 Waste management strategy

\begin{tabular}{lllll}
\hline Type of hospital & Waste storage facility & Waste disposal vehicle & Waste handling method & Recycling \\
\hline Referral & 25 & 12.5 & 94 & 2 \\
Private & 77 & 67 & 100 & 11 \\
Primary H. C. & 73 & 4 & 100 & 7
\end{tabular}

Source: Field survey, 2008.

Table 8 Training program and management team

\begin{tabular}{lll} 
Type of hospital & Training program & Waste management team \\
\hline Referral & 12.5 & 10 \\
Private & 33 & 44 \\
Primary H. C. & 13 & 33
\end{tabular}

Source: Field survey, 2008

\section{Conclusion}

In conclusion, these data suggested that the handling, treatment and the disposal strategy is not properly handled. Abatement facilities in form of autoclaving and incineration are not working adequately. ${ }^{17-21}$ The regulations required of every hospital to have inhouse incineration or off site facilities are not adequate enough.

As a result, proper handling methods, a step in reducing the bulk of hazardous waste should be encouraged as it will provide means of sorting out waste into categories for applicable disposal method. Actually, burning in the open should be discouraged. ${ }^{10}$ There must be clearly stipulated rules that apply to all persons who generate, collect, receive, store, transport, treat and dispose of, or handle medical waste in any form.

\section{Acknowledgments}

None.

\section{Conflicts of interest}

The authors declare there is no conflict of interest.

\section{References}

1. E-school today. Your cool fact and tips on waste management, copyright 2008-2015 eschool today in association with business Ghana.com. 2015

2. Eionet. European Topic Center on Resource and Waste Management, European Environmental Agency, EU as a recycling society. Working paper for the European Environmental Agency 2008 work programme. 2009 .

3. Armed K. Solid waste management seminal paper, October 62001. Solid waste management and collection/disposal of hazardous hospital waste. 2001

4. Oluwande PA. Effective urban solid waste management in developing country, NISER, Ibadan. 1993.

5. ADEC. Alaska Department of Environmental Conservation. Medical absent, like coding process, the coding process is $11.1 \%$, separations at source is practiced by the referral hospital with response of $60.4 \%$. Sharp segregation practices are average. Referral hospital is $54.8 \%$, private hospital is $55.6 \%$ while primary health center is $6.3 \%$. Disposal method commonly use in surveyed area is burning, $95 \%$ (referral hospital), $86.6 \%$ (public primary health centre) and $77.8 \%$ (private hospitals) (Table 8). waste disposal, Environmental health division. 2005.

6. Mathur V, Dwivedi S, Hassan M, et al. Knowledge, altitude and practice about biomedical waste management among healthcare personnel: A cross-sectional study. Indian J Community Med. 2011;36(2):143-145.

7. Leonard L, editor. Healthcare waste in South Africa; A civil society perspective. Processing international health care waste management, Conference and Exhibition; Johannesburg, South Africa; 2003.

8. Rao, SKM, Garg RK. A study of hospital waste disposal system in service hospital. Journal of Academy of Hospital Administration. 1994;6(2):27-31.

9. Chaerul M, Tanaka M, Shekdar AV. A system dynamics approach for hospital waste management. Waste Manag. 2008;28(2):442-449.

10. Rao S, Ranyal RK, Bhatia SS, et al. Biomedical waste management infrastructural survey of hospitals. Med J Armed Forces India. 2004;60(4):379-382.

11. ADEM. Alabama Department of Environmental Management, A guide to the handling and disposal of medical waste. 1990.

12. WHO. Understanding and simplifying bio-medical waste management. A training manual for trainers. 2005.

13. Bassey EB, Benka coker MO, Aluyi HSA. Characterization and management of solid medical waste in the Federal capital territory; Abuja, Nigeria. Department of medical laboratory services, General hospital Wuse, Abuja. Afr Health Sci. 2006;6(1):58-63.

14. Community options for safe needle disposal. United State Environmental Protection Agency. 2004.

15. Monyele SV, Anicetus H, Bilia MH. Globalization and effect on medical waste management in Tanzania, IET annual conference and general meeting 4th - 5th December 2003 AICC Arusha, Tanzania. 2003.

16. Blackman WC. Basic hazardous waste management. 2nd ed. Michigan, USA: Lewis publishers; 1996.

17. Acharya DB, Singh M. The book of hospital waste management. New Delhi: Mineerver Press; 2000:47.

18. Daniel DC, John PR, Oliver SD. Sustainable waste management. Natural Resource Conservation. 2002:454-471

20. Hassronge HTN. Medical waste management. Eastern Mediterranean health journal. 2001;7:1017-1024.

21. WHO. Save management of waste from health care activities. 2nd ed. Malta; 1999.
19. Daniel BB, Edwar AK. Environmental science. 1995:575-579. 